الجدارة الانتاجية والمائية لأهم أصناف محصول الأرز في جمهورية مصر العربية

$$
\text { منى عبد الحليم طلعت } 1
$$

الفدان دون الاهتمام بإنتاجية المتر المكعب من المياه لمحصول الأرز.

وقث اعتمد البحث على الطرق الموضوعية المبنية على مبدأ المعاينة والقياس الفعلي المعروفة باسم تجارب الحصاد. وقد توصل البحث إلى أن إجمالي مساحة محصول الأرز عام

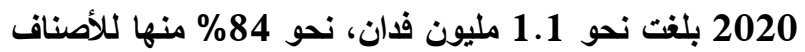
جيزة 178 (30.7\%) يليه الصنف سخا 101 (25.2\%) ثم الصنف جيزة 177 (14.3\%) ثم الصنف سخا 104 (14.2\%) باقى الأصناف شغلت نحو 15\% فقط. هذا وقدرت الإنتاجية على مستوى الجمهورية في هذا العام

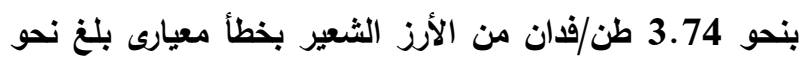

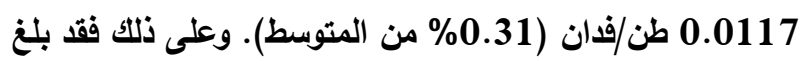
إجمالى إنتاج محصول الأرز الثعير عام 2020 نحو 4.19 مليون طن.

وقد بلغت مساحة الأصناف قصيرة العمر وفقا لاجراء 321

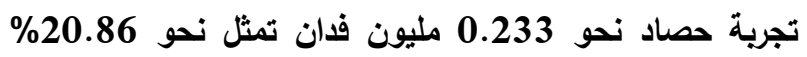
من إجمالى مساحة الأرز. وتم تقدير متوسط الإنتاج بنحو 3.619 طن/فدان بخطأ معيارى بلغ نحو 0.023 طن/فدان بنسبة نحو 049\% \% ويلغ متوسط استهلاك الأصناف قصيرة العمر من مياه الرى نحو 4742 م3/فدان. وأن متوسط إنتاج المتر المكب من المياه بلغ نحو 0.7630 كجم/م². وكاتت أهم الأصناف عالية الإنتاجية والموفرة للمياه فى هذه الفئة مرتبة تنازليا وفقا للإنتاجية هى: سوير 300 وجيزة 179

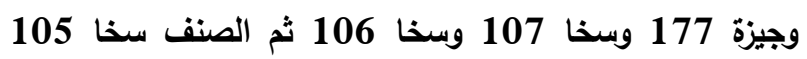
ويلغت الجدارة الإتتاجية الأرضية لهذه الفئة نحو 96.4\% وجئة

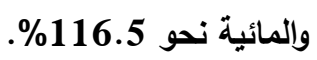
أما الأصناف متوسطة العمر فقا بلغت مساحتها نحو 0.885 مليون فدان تمثل نحو 79.14\% من إجمالى مساحة

$$
\text { الملخص العربى }
$$

تهذف الإستراتيجية الزراعية إلى إحداث نهضة زراعية شاملة

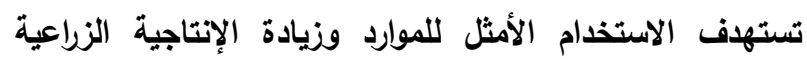
لوحتي الأرض والمياه. ونظرا لمحدوية الموارد المائية الطبيعية في مصر فإن استراتيجية التنمية الزراعية تستهذف ترشيد استخدام مياه الري في الزراعة لمختلف المحاصيل وخاصة محصول الأرز. ونظرا لأن الأرز من المحاصيل الثرهه في استخدام مياه الري حيث يستهلك وحده نحو 30\% من إجمالى استهلاك المحاصيل

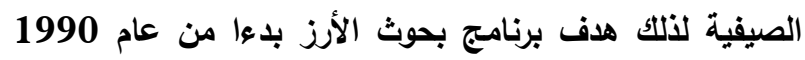

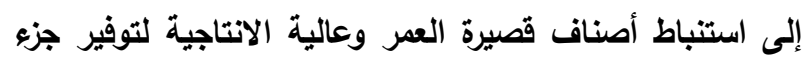
كبير من مياه الري يقدر بنحو 20-30\% من استهلاك الأصناف القديمة.

ويهذف هذا البحث إلى تقييم الإنتاجية الأرضية والمائية

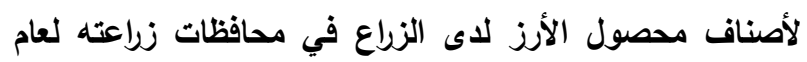
2020 حتى يمكن المساعدة في وضع إستراتيجية واقعية لأهم الأصناف التي تحقى أعلى إنتاجية مع الاستخدام الأمثل لمياه

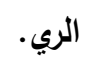

وتتلخص مشكلة البحث في أنه على الرغم من احلال أصناف

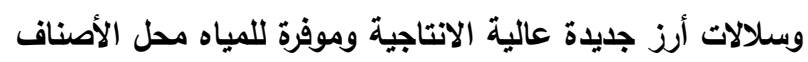

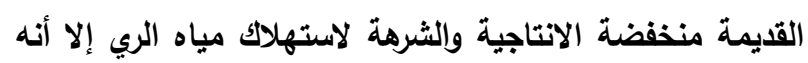

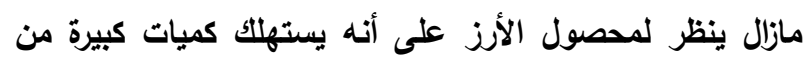
مياه الري مما يؤثر بشكل سلبي على المحاصيل الأخرى ويالتالي يؤثز في التوسع الأفقي من المحاصيل الزراعية. والكثير من زراع محصول الأرز لم يحققوا بعد المحصول الاقتصادي، كما أن النشرات الإحصائية تركز على حساب إنتاجية

معرف الوثيقة الرقمي: 2021.188821/asejaiqjsae. 10.21608 1معهز بحوث الإقتصاد الزراعى - مركز البحوث الزراعية استلام البحث فى 15 يوليو 2021، الموافقة على النشر فى الزئ الزراعية أغسطس 2021 
بيانات سليمة. ويستخدم في مصر حاليا أكثر من طريقة لجمع البيانات عن هذا الإنتاج: - الطريقة التقليدية وتعتمد على السؤال والحكم الثخصي للمسئولين عن الإنتاج الزراعي، لذلك فهي عرضة لأخطاء التحيز الثخصي.

- الأسلوب الثاني بدأ عام 1955 في مصر ويعتمد على طرق موضوعية مبنية على مبدأ المعاينة العشوائية

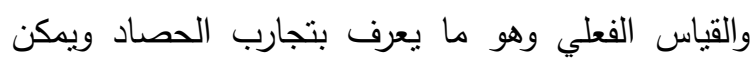
معه الحصول على تقديرات موثوق بها ومعلومة الدقة، ونظرا لما يصاحبها من تكلفة عالية وجهد كبير فتطبق على عدد محدود من المحاصيل الاستراتيجية الهامة منل ملك

$$
\text { القمح والأرز والقطن والذرة. }
$$

ونظرا للأهمية التي بتصف بها الأرز فى مصر حيث يعتبر من المحاصيل الغذائية الهامة، كما يأتي في المرنبة الثانية بعد القمح من حيث أهميته كغذاء للشعب المصري، إضافة إلى احتوائه على عناصر غذائية متعددة وضرورية

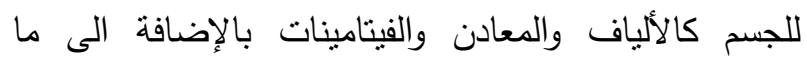
يتصف به من قلة الدهون والكولسترول وعدم وجود الصوديوم وقلة الأملاح ومحدودية السعرات الحرارية. كما يعتبر كذلك

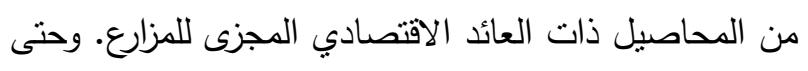
يمكن رسم سياسة صنفية لترشيد استخدام المياه مع الحصول على أعلى انتاجية فى نفس الوقت بتطلب ذلك تقدير انتاجية محصول الأرز على مستوى الأصناف لدى زراع المحصول بالاستعانة بمسوحات المعاينة والقياس الفعلي لقياس الكفاءة الانتاجية الأرضية والمتمثلة في منتسط إنتاج الفدان من محصول الأرز والكفاءة الإنتاجية المائية منمثلة في إنتاجية المنز المكعب من الماء لمختلف أصناف محصول الأرز الألتاهيه بمختلف مناطق زراعته مما يساعد هذا في التعرف على منى مقدار الفجوة بين إنتاجية المحصول لدى الزراع والمحصول الاقتصادي الموصى به من قبل الهيئات البحثية لمحصول
محصول الأرز عام 2020. ويلغ عدد تجارب الحصاد التى تم تنفيذها لتقدير إنتاجية المحصول 1071 تجرية حصاد قدرت إنتاجية هذه الأصناف بنحو 3.755 طن/فدان أرز شعير بخطأ

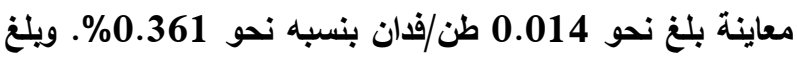
متوسط استهلاك الأصناف متوسطة العمر من مياه الرى نحو

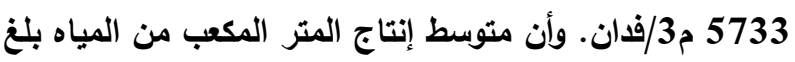

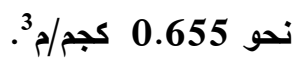
وكانت أهم الأصناف مرتبة حسب جدارتها الانتاجية والمائية كما يلى: سخا 108 وجيزة 178 وهجين 104 وسخا 101 ثم سخاتها .104 وقد بين البحث أن الفجوة بين إنتاجية أصناف محصول الأرز

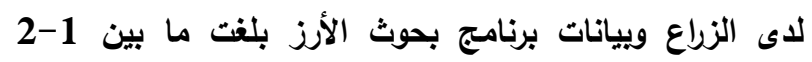

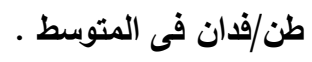
ووفقا لبيانات وزارة الموارد المائية والرى فإن المقتن المائى

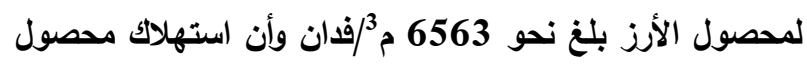
الأرز بلغ نحو 7.9 مليار متر مكعب يمثل نحو إجمالى استهلاك المحاصيل الصيفية. فى حين أن الأصناف العديثة قصيرة العمر ومتوسطة العمر

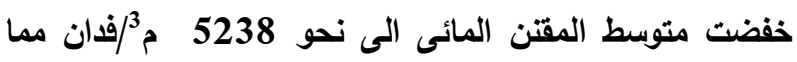
نتج عنه انخفاض كميات المياه المستخدمة من محصول الأرز

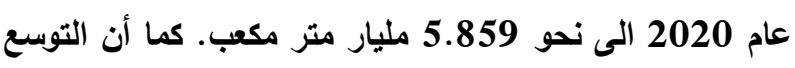
فى زراعة الأصناف قصيرة العمر يمكن أن يوفر نحو 4 مليار متر مكعب إضافية. الكلمات المفتاحية: أصناف الارز - تجارب الحصاد -الكفاءة - إنتاجية المياه

\section{المقدمةة}

بعتبر قطاع الزراعة أحد القطاعات الرئيسية الهامة في

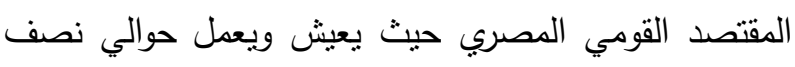
عدد سكان مصر البالغ حاليا نحو 100 مليون نسمة، ومن ثم فإن الحصول على إحصاءات دقيقة عن الإنتاج الزراعي في وقت مبكر يعتبر أمرا ضروريا لرسم السياسة الاقتصادية

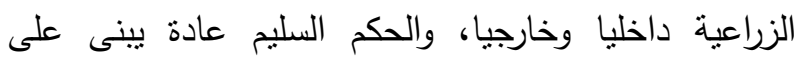


1-مسوحات المعاينة لتقدير محصول الأرز بطريقة العينات المنفذة بواسطة المناطق الاحصائية بالمحافظات تحت اشراف

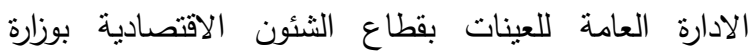

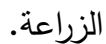

2-مركز البحوث الزراعية، البرنامج القومى لبحوث محصول

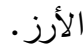
3-وزارة الموارد المائية والرى. 4- الجهاز المركزى للتعبئة العامة والاحصاء. الطريقة البحثية واسلوب اختيار عينة البحث:

اعتمد البحث على الطرق الموضوعية المبنية على مبدأ المعاينة والقياس الفعلى المعروفة باسم تجارب الحصاد للحصول على تقديرات موثوق بها ومعلومة الدقة وخالية من التحيز الثخصي وذللك بالتعاون مع الادارة العامة للعينات بقطاع الثئون الاقتصادية بوزارة الزراعة حيث نم تصميم معاينة طبقية متعددة المراحل لتقدير انتاجية محصول الأرز حيث تشكل مجموعة الأحواض (200 فدان أرض مزروعة فى المتوسط) وحدة المعاينة الأولية (PSU) وحقل الأرز وحدة

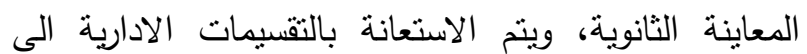
التقبيم الطبقى بالمحافظة. بعد تحديد عدد مجموعات الأحواض المناسب لتقدير محصول الأرز فى الطبقة.

$$
\text { تتلخص مراحل الاختيار العشوائى فى: }
$$$$
\text { 1- اختيار مجموعات الأحواض لكل طبقة. }
$$

2-حصر زراع محصول الأرز بالتجاور داخل مجموعة الأحواض المختارة ثم اختيار عدد 2 حقل مزروع بمحصول الأرز عشوائيا بكل مجموعة مختارة. 3- اختيار تربيعة واحدة داخل كل حقل مختار .

4-تحديد قطعة حصاد محددة الأبعاد (2م x 2م) داخل

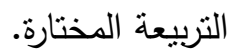
يتم يوم الحصاد حصاد القطعة وفصل الحبوب ووزن العينة وتتولى المناطق الاحصائية بالمحافظات تتفيذ تجارب
الأرز . هذا بالإضافة للمساعدة على تقدير الاستهلاك الفعلي

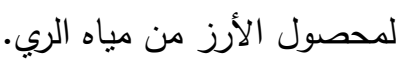

\section{المشكلة البحثية}

بالرغم من استتباط واحلال أصناف وسلالات أرز جديدة عالية الانتاجية وموفرة للمياه محل الأصناف القديمة منخفضة الانتاجية والثرهة لاستهلاك مياه الرى، إلا أنه مازال ينظر

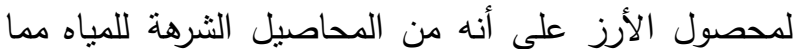
ينعكس ذللك على دقة التعرف على الميزان المائي الفعلي لري المحاصيل الزراعية والمساحة الفعلية المطلوب زراعتها من تلك المحاصيل. والكثثر من زراع محصول الأرز لم يحققوا بعد المحصول الاقتصادي. كما أن النشرات الاحصائية تركز على حساب إنتاجية الفدان دون الاهتمام بإنتاجية المتر المكعب من المياه

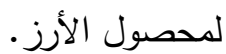

\section{الاهد|ف البحثية}

1- يهذف هذا البحث إلى استخدام أساليب المعاينة والقياس الفعلي (الطرق الموضوعية objective methods) للحصول على تقديرات موثثق بها ومعلومة الدقة لمختلف أصناف محصول الأرز لاى زراع المحصول هولى ويشمل ذلك تقدير متوسط إنتاج الفدان وخطؤه المعياري ومتوسط انتاجية المتر المكعب من مياه الري.

2- المقارنة بين ما يحصل عليه زراع محصول الأرز وبين الانتاجية المفروض الحصول عليها وفقا لتوصيات البرنامج القومى لبحوث الأرز للأصناف الحديثة عالية

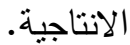

3- ترتيب الأصناف الجديدة حسب جدارتها الانتاجية الأرضية والمائية للمساعدة فى رسم سياسة صنفية تقلل من استخدام مياه الرى مع الحصول على أعلى انتاجية.

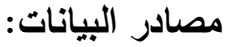
تم الحصول على البيانات من المصادر التالية: 
حيث: As هى مساحة المحصول فى الطبقة S

= هى مجموع مساحة المحصول بالمحافظة. 4- تباين متوسط محصول المحافظة y يقدر بالآتى:

$$
\mathrm{V}\left(\mathrm{y}_{\mathrm{s}}\right)=\frac{\sum A_{S}^{2} v\left(\overline{\mathrm{y}}_{S}\right)}{\left(\sum A_{s}\right)^{2}}
$$

\section{الإطار النظرى للبحث: - (البث:}

تعنبر قضية تأمين الغذاء من أهم القضايا الاستراتيجية التى تتال اهتمام الدولة لما لها من أبعاد اجتماعية واقتصادية

وسياسية، وتهدف استراتيجية وزارة الزراعة الى:

1-الاستخدام الأمنل للموارد الزراعية الطبيعية.

2-زيادة الانتاجية الزراعية لوحدتى الأرض والمياه.

3-رفع معدلات الاكتقاء الذاتى من المحاصيل الزراعية

الاستراتيجية لتقليل الفجوة الغذائية.

4-تدعيم القدرة التتافية للمنتجات الزراعية فى الاسواق

$$
\text { المحلية والدولية. }
$$

5-تحسين مناخ الاستثمار الزراعى.

6-تحسين مستوى معيشة سكان الريف.

تعانى مصر فى السنوات الأخيرة من شح شديد فى

المياه، ويعد توزيع المياه غير المتكافئ واساءة استخدام موارد المياه وتقنيات الرى غير الفعالة من العوامل الرئيسية التى ولى ليعياه

تلعب دورا سلبيا على الأمن المائى فى البلاد.

ويعد نهر النيل مصدر المياه العذبة الرئيسى فى مصر

حيث يوفر 95\% من اجمالى استخدام المياه. ومع ذلك نواجه مصر تهديدا بنقص حاد فى المياه خلا العقد القادم يقدر بنحو 7 مليار منز مكعب كل عام، ومن المتوقع نزايد الطلب على المياه بنحو 25\% في عام 2025.

وتثير دراسة قومية عن موارد المياه فى مصر أعدها

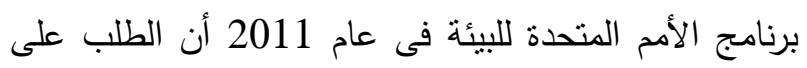
المياه قد بلغ 80 مليار متر مكعب سنويا (برنامج الأمم
الحصاد وتسجيل وارسال النتائج للادارة العامة للعينات وقد

بلغ حجم العينة 1392 تجربة.

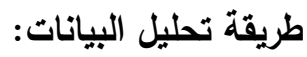

استخدم فى تحليل بيانات عينة البحث طريقة تقدير

متوسط محصول الأرز فى الطبقة، وهى تتناسب مع تصميم التجارب التى اتبعت فى جمع البيانات، والتى تم فيها اختيار تربيعة واحدة فقط بكل قطعة محددة فى الحقل، ومن ثم يمكن اعتبار أن متوسط المحصول المقدر من كل طبقة هو تقدير كوسط حسابى لجميع المشاهدات بهذه الطبقة، ومن خلاله يمكن أيضا تقدير نباين المتوسط بإجراء تحليل التباين لمحصول القطع. وعلى ذلك فإنه يمكن تقدير : 1- منوسط المحصول للطبقة وليكن ys بما يأنى:

$$
\mathrm{y}_{\mathrm{s}}=\frac{\sum^{n} \sum^{m} y_{i j}}{\mathrm{~nm}}
$$

حيث: yij = ناتج القطعة من الحقل رقم J فى المجموعة رقم i

n = ع = عدد الحقول المختارة فى المجموعة $=$ = عدد المجموعات المختارة فى الطبقة 2- بمكن الحصول على تباين هذا التقدير من العينة بالآتى:

$$
\mathrm{V}\left(\mathrm{y}_{\mathrm{s}}\right)=\frac{S_{b}^{2}}{n m}
$$

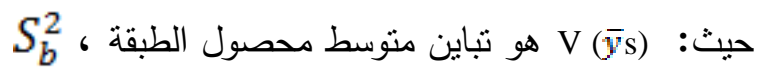
هو منوسط المربعات بين المجموعات للقطعة فى تحليل التباين للعينة. 3- يمكن وزن تقديرات الطبقات المختلفة بمساحة المحصول كى ينتج منتوسط المحصول للمحافظة وكذا تباينه وعلى ذلك:

$$
\mathrm{y}=\frac{\sum A_{s} \cdot \overline{\mathrm{y}}_{S}}{\sum A_{s}}
$$


المائية المتاحة للمحاصيل الاستراتيجية الأخرى. وأن الأسلوب الأمتل لحساب الربح والخسارة فى ظل محدودية الموارد

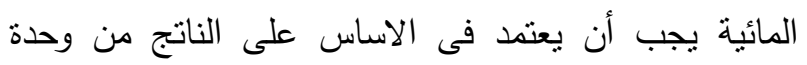

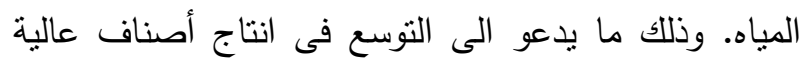
الانتاجية قصيرة العمر وهو ما يؤدي إلى تخفيض استهلالك المياه ويحقق زيادة فى معدلات التكثيف المحصولى.

\section{السياسة الصنفية لمحصول الأزز:}

بدأت خطة عمل وزارة الزراعة في مصر ومركز البحوث الزراعية نظوير واستتباط أصناف عالية الانتاجية مبكرة النضج من خلال تنفيذ العديد من البرامج البحثية منذ أوائل تسعينات القرن الماضى (1990) وبالتعاون والتتسيق وتبادل

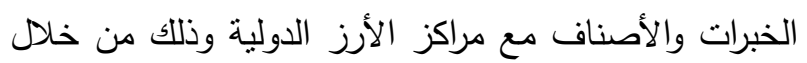
برنامج محكم ذى أهداف محددة لتربية أصناف جديدة من الأرز تهذف إلى رفع الاتتاجية إلى مسنوياتها العالمية

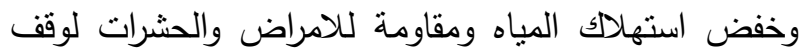
استخدام المبيدات نهائيا لمحصوا الأرز.

الأصناف القديمة لمحصول الأرز في مصر أهمها جيزة 170 وجيزة 171، مدة مكث المحصول منذ الزراعة وحتى الاصنى

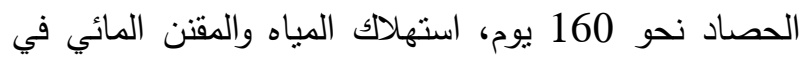

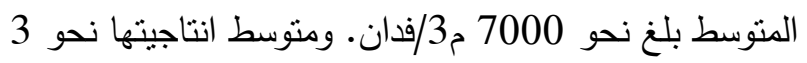

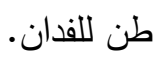

وقد تلخصت خطة عمل الوزارة فى استتباط أصناف حديثة بعضها منوسط العمر 130-140 يوم فى المتوسط منل أصناف سخا 101، سخا 104، سخا 108، جيزة 178

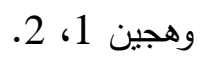

وأصناف مبكرة النضج 120-125 يوم انتاجيتها عالية أكثر من 4 طن للفدان مثل أصناف جيزة 177، جيزة 179، وسخا 102 وسخا 103 وسخا 105، وسخا 106، سخا 107 استهلالك المياه لهذه الأصناف بتراوح بين 400 وسخا 5000
الهتحدة للبيئة، "موارد المياه فى مصر"، 2011). ، فى حين أن حصة مصر من مياه نهر النيل فى ظل اتفاقية مياه النيل لعام 1959 نصل الى 55 مليار مثر مكعب سنويا. أى أن فيان في الن كمية المياه المتاحة لمصر من مياه نهر النيل ثابته، بالرغم

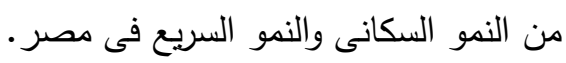
ويحتم شح المياه على الحكومة الصصرية وجميع السكان التحرك بسرعة وبشكل حاسم للتخفيف من شح المياه وتطبيق

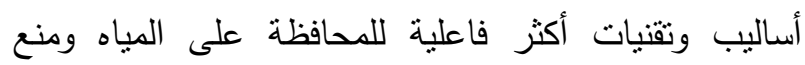
تلوثها ووضع وتطوير خطط من شأنها جعل نتنبات الرى الرى أكثر فاعلية وكفاءة.

ونظرا لمحدودية الموارد المائية الطبيعية فى مصر حيث تنلغ حصة مصر من مياه النيل نحو 55.5 مليار متر مكعب وهى حصة ثابته بالرغم من النمو السكانى اضافة الى لئى محدودية كميات المباه الجوفية وقلة الأمطار فإن استراتيجية التتمية الزراعية تستهدف ترشيد استخدامات مياه الرى فى التى

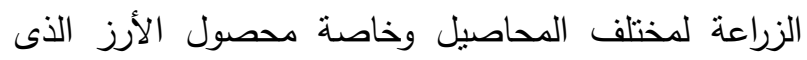
يستهلك وحده نحو 30\% من اجمالى الكميات المستخدمة للمحاصيل الصيفية. ويعتبر الأرز من المحاصيل الغذائية والتصديرية الهامة

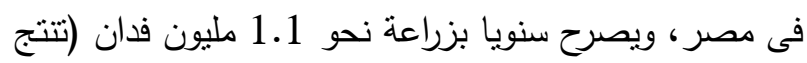
نحو 4 مليون طن أرز شعير) فى الأماكن القريبة من البحر المتوسط والبحيرات وقد تضمنت خطة زراعة الأرز عام 2020 أن يتم زراعته فى مساحات تغطى محافظات (كفر الثيخ 189800 فدان، البحيرة 106650 فدان، الدقهلية 182550 فدان، الثرقية 127850 فدان، الغربية 40600 فدان، دمياط 42000 فدان، الاسماعيلية 2750 فدان) وذلك لضمان وجود أكبر ضاغط مدكن للمياه العذبة لوقف تداخل

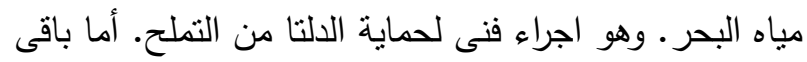

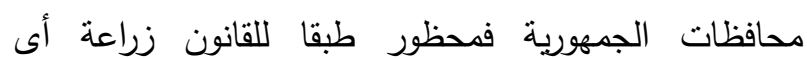

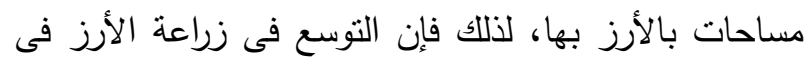

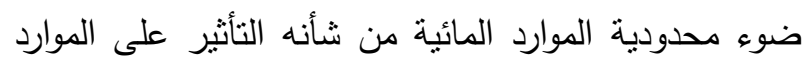


سخا 101: وهو صنف عريض الحبوب عالى المحصول، إنتاجه من 4.5 إلى 5 طن/فدان، قصير الساق، فنزة نموه 140 يوم، منوسط التحمل للملوحة، وحساس لمرض اللفحة. سخا 104: صنف عريض الحبوب، طويل الساق، متوسط إنتاجه من 4 إلى 4.5 طن/فدان، حساس لمرض اللفحة،

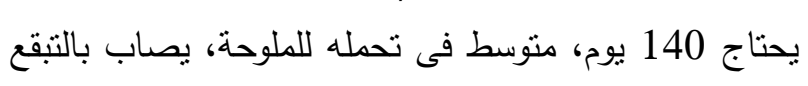
البنى، وقد تتعرض النباتات للرقاد.

سخا 107: صنف مصري قصير الحبة، مقاوم للرقاد، مبكر النضج حيث يحتاج إلى 125 يوم من الزراعة للحصاد، يتحمل الجفاف (نقص مياه الري)، منوسط فى تحمله للملوحة، مقاوم للفحة، إنتاجية الفدان من 4- 4.5 طن/فدان تحت ظروف الرى العادى، وتبلغ الإنتاجية من 3 - 3.5 طن/فدان تحت ظروف نقص المياه.

سخا 108: صنف أرز حديث عالي الإنتاجية وغزير التفريع، فترة النمو تتراوح من الزراعة حتى الحصاد من 125

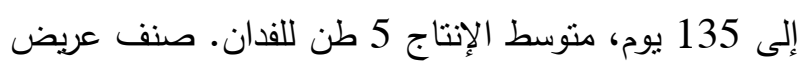
الحبة، مقاوم لمرض اللفحة، يتحمل ندرة المياه والجفاف والمياه المخلوطة والأراضى التى تعانى من مشاكل الملوحة والقلوية، ولا يميل للرقاد.

سخا سوير 300: وهو من الأصناف الجديدة التى تتفوق فى المحصول، ويتحمل الظروف السيئة، حيث يعتبر من الطرز الحديثة، المتحملة لنقص المياه، كما يتحمل الري بالمياه المخلوطة، ويتفوق فى صفات جودة الحبوب، ويحقق انتاجية تصل إلى 5 طن للفدان، ويحقق أيضا وفرا فى استهلاك المياه، يصل إلى 2000 منز مكعب للفدان، حيث يستهلك الفدان 4 آلاف متر مكعب فقط.

الأرز الهجين: صنف رفيع الحبة، منوسط إنتاجه من 5.5

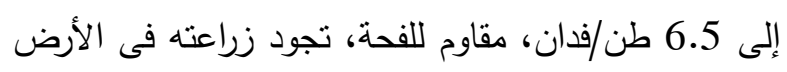
المالحة.
وقد تم تعميم زراعة هذه الأصناف فى عام 2002 حيث غطت نحو 98\% من مساحة محصول الأرز. ونتيجة لحصاد الأصناف المبكرة فى النضج فى منتصف شهر أغسطس وأوائل شهر سبتمبر بدلا من أكتوبر ونوفمبر وبالتعاون مع وزارة الموارد المائية والرى حقق تعميم زراعة

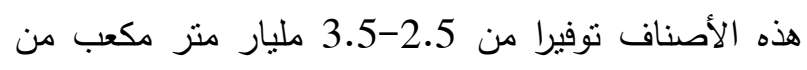
المياه، كما تم استحداث دورات زراعية وتعاقبات محصولية جديدة لتعظيم انتاجية وحدة المساحة. الأصناف الجليدة للأرز المستخدمه حاليا فى قطاع الزراعة وفى تجارب البحث: أن السياسة الصنفية لمحصول الأرز تتضمن مجموعة من الأصناف تحقق جميع رغبات المزارع والمستهلك وذلك من حيث تحملها لطول فترات الرى بمختلف نوعية المياه المستخدمة وجودة الأراضى المنزرعة فيها (وزارة الزراعة

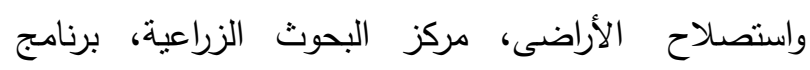
الأرز، معهز بحوث المحاصيل الحقلية، التوصيات الفنية لمحصول الأرز) وهذه الأصناف هى: جيزة 177: وهو صنف قصبر الحبوب، قصير الساق، فترة نموه 125 يوم من الزراعة حتى الحصاد، إنتاجيته من 3.5 إلى 4 طن/فدان. مقاوم للفحة ويصاب بالتبقع البنى، يجود

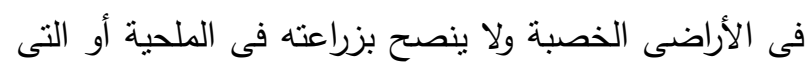
تروى بمياه مخلوطة.

جيزة 178: صنف قصير الحبوب، عالى المحصول، متوسط إنتاجه من 4-5 طن/فدان، من الأصناف قصيرة

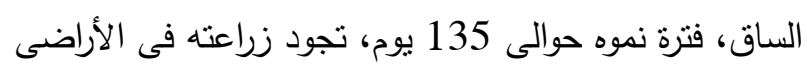
الخصبة والملحية، ويقاوم مرض اللفحة. جيزة 179: صنف مصرى متوسط فى طول الحبوب، منوسط إنتاجه من 4.5 إلى 5 طن/فدان، مقاوم للفحة يحتاج إلى 120 يوم من الزراعة للحصاد بطريقة الثتل، تجود زراعته فى الأراضى الملحية ومتحمل لظروف العطش. 
3.81 طن/فدان على التوالى. هذا وقد بلغ المتوسط العام نحو

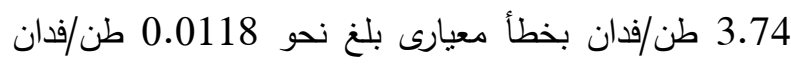
.$(\% 0.31)$

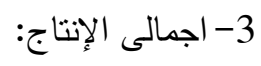

بلغ إجمالى انتاج محصول الأرز عام 2020 نحو 4.19 مليون طن مقابل نحو 4.7 مليون طن عام 2019 أى الى بانخفاض قدر بنحو 0.51 مليون طن نسبته تبلغ نحو

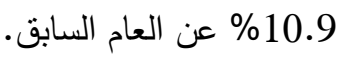

وبيانات انتاج أهم الأصناف عام 2020 من الأرز كما يلى: - جيزة 178 نحو 1309.8 ألف طن بنسبة بلغت نحو \%31.29 - سخا 101 نحو 1044.1 ألف طن بنسبة بلغت نحو \%24.95 - جيزة 177 نحو 594.1 ألف طن بنسبة بلغت نحو \%14.19 - سخا 104 نحو 575.6 ألف طن بنسبة بلغت نحو \%13.75

جدول 1- أ. تقلير الإنتاجية لأصناف محصول الأرز الصيفى عام 2020 بإستخدام أسلوب المعاينة العشوائية المقترنة

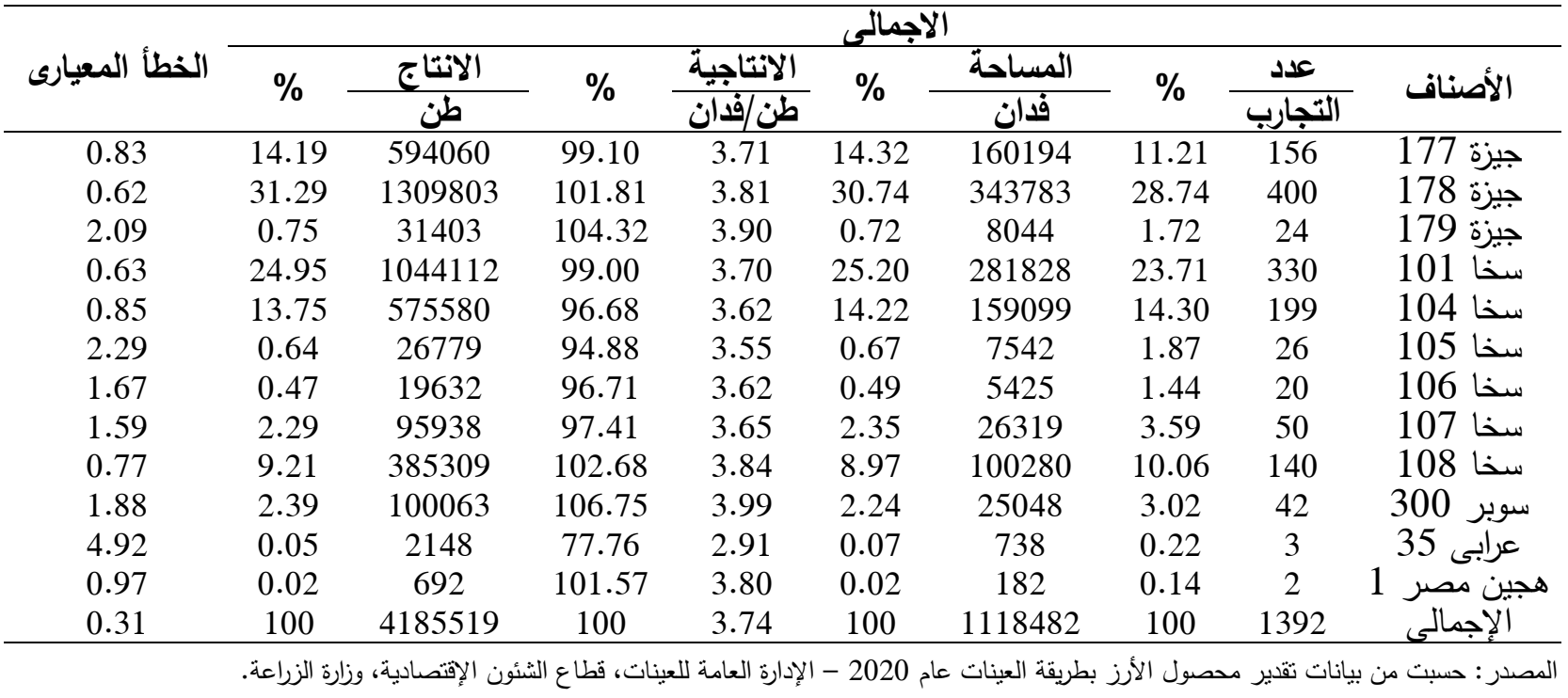

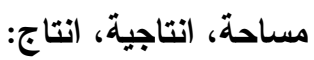
بتضح من الجدولين رقم (2-أ)، (2-ب) ما يلى:

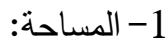

بلغ اجمالى مساحة محصول الأرز عام 2020 وكما حدنها وزارة الموارد المائية والرى نحو 1.1 مليون فدان مقسمة

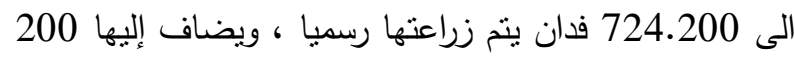

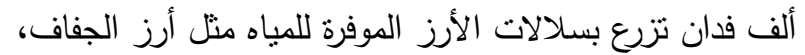
وكنلك 150 فدان تزرع من المياه ذات الملوحة المرتفعة (وزارة الموارد المائية والرى، قرار وزارى رقم 305 لسنة 2020). نحو 84.5\% من مساحة محصول الأرز عام 2020 هى هي للأصناف جيزة 178 (30.7\%)، وسخا 101 (25.2\%)، وجيزة 177 (14.3\%)، بعد ذلك يأنى الصنف سخا 104

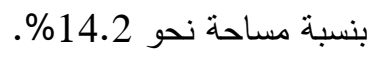
2- 2 - 2 انتاجية الأصناف: وبالنسبة للانتاجية كان سوبر 300 أعلى الأصناف (3.99 طن/فدان)، يليه جيزة 179 بانتاجية بلغت نحو 3.90 ، ثم الثران الصنفين سخا 108 وجيزة 178 بانتاجية بلغت نحو 1.84 3.
أولا: الأهمية النسبية لأصناف محصول الأزز عام 2020

\begin{tabular}{|c|c|c|c|c|c|c|c|c|c|}
\hline \multirow[b]{2}{*}{ الخطأ المعيارى } & \multicolumn{9}{|c|}{ الاجمالى } \\
\hline & $\%$ & الانتاج & $\%$ & طن/فانانية & $\%$ & المسانة & $\%$ & التجارب & الأصناف \\
\hline 0.83 & 14.19 & 594060 & 99.10 & 3.71 & 14.32 & 160194 & 11.21 & 156 & جيزة 177 \\
\hline 0.62 & 31.29 & 1309803 & 101.81 & 3.81 & 30.74 & 343783 & 28.74 & 400 & جيزة 178 \\
\hline 2.09 & 0.75 & 31403 & 104.32 & 3.90 & 0.72 & 8044 & 1.72 & 24 & جيزة 179 \\
\hline 0.63 & 24.95 & 1044112 & 99.00 & 3.70 & 25.20 & 281828 & 23.71 & 330 & سخا 101 \\
\hline 0.85 & 13.75 & 575580 & 96.68 & 3.62 & 14.22 & 159099 & 14.30 & 199 & سخا 104 \\
\hline 2.29 & 0.64 & 26779 & 94.88 & 3.55 & 0.67 & 7542 & 1.87 & 26 & سخا 105 \\
\hline 1.67 & 0.47 & 19632 & 96.71 & 3.62 & 0.49 & 5425 & 1.44 & 20 & سخا 106 \\
\hline 1.59 & 2.29 & 95938 & 97.41 & 3.65 & 2.35 & 26319 & 3.59 & 50 & سخا 107 \\
\hline 0.77 & 9.21 & 385309 & 102.68 & 3.84 & 8.97 & 100280 & 10.06 & 140 & سخا 108 \\
\hline 1.88 & 2.39 & 100063 & 106.75 & 3.99 & 2.24 & 25048 & 3.02 & 42 & سوبر 300 \\
\hline 4.92 & 0.05 & 2148 & 77.76 & 2.91 & 0.07 & 738 & 0.22 & 3 & عرابى 35 \\
\hline 0.97 & 0.02 & 692 & 101.57 & 3.80 & 0.02 & 182 & 0.14 & 2 & هجين مصر 1 \\
\hline 0.31 & 100 & 4185519 & 100 & 3.74 & 100 & 1118482 & 100 & 1392 & الإجمالي \\
\hline
\end{tabular}




$$
\text { مجلة الإسكندرية للتبادل العلمى - (مجلد42 العدد 3) يوليو - سبتمبر } 2021
$$

جدول 1-ب.الأهمية النسبية لأصناف الأرز عام 2020

\begin{tabular}{|c|c|c|c|c|c|c|c|c|}
\hline \multirow[b]{2}{*}{$\%$} & \multicolumn{2}{|l|}{ الانتاج } & \multirow[b]{2}{*}{ SE \% } & \multirow{2}{*}{ طن/انانية } & \multirow[b]{2}{*}{ تجميعى\% } & \multirow[b]{2}{*}{$\%$} & \multirow{2}{*}{ ألف فدان } & \multirow{2}{*}{ مرتبة تنازليا حسب الأصناف } \\
\hline & ألف طن & \% من المتوسط & & & & & & \\
\hline 31.29 & 1309.8 & 101.81 & 0.62 & 3.81 & 30.74 & 30.7 & 343783 & 1- جيزة 178 \\
\hline 24.95 & 1044.1 & 99.00 & 0.63 & 3.70 & 55.93 & 25.2 & 281828 & 2- سخا 101 \\
\hline 14.19 & 594.1 & 99.10 & 0.83 & 3.71 & 70.26 & 14.3 & 160194 & 3- جيزة 177 \\
\hline 13.75 & 575.6 & 96.68 & 0.85 & 3.62 & 84.48 & 14.2 & 159099 & 4- سخا 104 \\
\hline 9.21 & 385.3 & 102.68 & 0.77 & 3.84 & 93.45 & 9.0 & 100280 & 5- سخا 108 \\
\hline 2.29 & 95.9 & 97.41 & 1.59 & 3.65 & 95.80 & 2.4 & 26319 & 6- سخا 107 \\
\hline 2.39 & 100.1 & 106.75 & 1.88 & 3.99 & 98.04 & 2.2 & 25048 & 7- سوبر 300 \\
\hline 0.75 & 31.4 & 104.32 & 2.09 & 3.90 & 98.76 & 0.7 & 8044 & 8- جيزة 179 \\
\hline 0.64 & 26.8 & 94.88 & 2.29 & 3.55 & 99.43 & 0.7 & 7542 & 9- سخا 105 \\
\hline 0.47 & 19.6 & 96.71 & 1.67 & 3.62 & 99.92 & 0.5 & 5425 & 10-سخا 106 \\
\hline 0.05 & 2.1 & 77.76 & 4.92 & 2.91 & 99.98 & 0.07 & 738 & 11 -عرابى 35 \\
\hline 0.02 & 0.7 & 101.57 & 0.97 & 3.80 & 100 & 0.02 & 182 & 12-هجين مصر 1 \\
\hline 100 & 4185.5 & 100 & 0.31 & 3.74 & 100 & 100 & 1118482 & الإجمالى \\
\hline
\end{tabular}

كذلك يوضح الجدول رقم (3) الكفاءة الانتاجية الفدانية والمائية لمختلف الأصناف منسوبة الى متوسط الأصناف متوسطة العمر=100. ويتبين من الجدول أن الصنف سوبر 300 يأنى فى المرتبة الأولى بالنسبة للانتاجية الأرضية كما يأتى أيضا فى الترتيب رقم 1 بالنسبة للانتاجية المائية، والتزتيب رقم 7 بالنسبة للمساحة.

ويأنى الصنف جيزة 179 فى المرتبة الثانية بالنسبة للانتاجية الأرضية، كما أنه يأنى فى الترتيب رقم 4 بالنسبة للانتاجية المائية، والترتيب رقم 8 بالنسبة للمساحة. أما الصنف سخا 108 فيأتى فى المرتبة الثالثة بالنسبة للانتاجية الأرضية، كما أنه يأتى فى الترتيب رقم 6 بالنسبة للانتاجية المائية، والتزتيب رقم 5 بالنسبة للمساحة. والصنف جيزة 178 فيأتى فى المرتبة الرابعة بالنسبة للانتاجية الأرضية، كما أنه يأتى فى الترتيب رقم 9 بالنسبة للانتاجية المائية، والتزتيب رقم 1 بالنسبة للمساحة. أما الصنف هجين مصر 1 فيأتى فى المرتبة الخامسة بالنسبة للانتاجية الأرضية، كما أنه يأتى فى الترتيب رقم 10 بالنسبة للانتاجية المائية، والترتيب رقم 12 بالنسبة للمساحة.
- سخا 108 نحو 385.3 ألف طن بنسبة بلغت نحو .$\% 9.21$

- سوبر 300 نحو 100.1 ألف طن بنسبة بلغت نحو .$\% 2.39$

- سخا 107 نحو 95.9 ألف طن بنسبة بلغت نحو .$\% 2.29$ - جيزة 179 نحو 31.4 ألف طن بنسبة بلغت نحو $\% 0.75$

ثانيا: الجدارة الانتاجية والمائية لأصناف محصول الأرز: يوضح جدول رقم(2) المساحة الفدانية لأصناف محصول الأرز مقسمة الى قصيرة العمر (120-125 يوم)، ومتوسطة العمر (130-140 يوم). ويتضمن الجدول أيضا انتاجية هذه الأصناف الفدانية (طن/فدان) وأخطائها المعيارية اضافة الى المقننات المائية لكل صنف وانتاجية المنز المكعب من المياه (كجم/منز مكعب). ومن أجل حساب الجدارة الانتاجية والمائية فقد تم ترتيب البيانات نرتيب تتازلى وفقا لكل من مساحة الأصناف، والانتاجية الفدانية، والانتاجية المائية، ويتضح ذلك فى جدول 
1613 منى عبد الحليم طلعت:: الجدارة الانتاجية والمائية لأهم أصناف محصول الأرز في جمهورية مصر العربية.

300 وجيزة 179 وسخا 108 وجيزة 178، اضافة الى

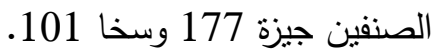

وبزيادة مساحة هذه الأصناف يمكن زيادة انتاج محصول

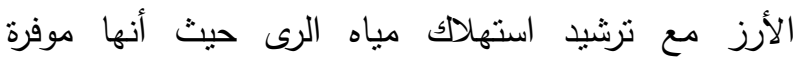

أما الصنف جيزة 177 فيأتى فى المرتبة السادسة بالنسبة للانتاجية الأرضية، كما أنه يأنى فى الترتيب رقم 5 بالنسبة الترنية للانتاجية المائية، والترتيب رقم 3 بالنسبة للمساحة. ويتضح من الجدولين (2 ،3) أن أهم الأصناف التى 3 يتوفر بها الجدارة الإنتاجية العالية الفدانية والمائية هى: سوبر الفين

جدول رقم 2. تقدير الجدارة الانتاجية والمائية لأصناف محصول الأزز بطريقة العينات عام 2020

\begin{tabular}{|c|c|c|c|c|c|c|c|c|c|}
\hline \multirow{2}{*}{ كجم/الإئتيةّة } & \multirow{2}{*}{ المقنن المائى } & \multirow{2}{*}{ المحصول يوم } & \multicolumn{2}{|c|}{ الخطأ المعيارى } & \multirow{2}{*}{ إلتناجط } & \multirow{2}{*}{ تجارب } & \multirow{2}{*}{ فالمان } & \multirow{2}{*}{ الأصناف } & \multirow{2}{*}{ مجموعة } \\
\hline & & & $\%$ & طن/فدان & & & & & \\
\hline 0.7064 & 5250 & 125 & 0.831 & 0.031 & 3.708 & 156 & 160194 & جيزة 177 & \\
\hline 0.7924 & 4600 & 125 & 1.591 & 0.058 & 3.645 & 50 & 26319 & سخا 107 & \\
\hline 0.7436 & 5250 & 125 & 2.094 & 0.082 & 3.904 & 24 & 8044 & جيزة 179 & \\
\hline 0.6763 & 5250 & 125 & 2.288 & 0.081 & 3.551 & 26 & 7542 & سخا 105 & قصبيرة العصر \\
\hline 0.6764 & 5350 & 127 & 1.667 & 0.060 & 3.619 & 20 & 5425 & سخا 106 & \\
\hline 0.9987 & 4000 & 122 & 1.876 & 0.075 & 3.995 & 42 & 25048 & سوبر 300 & يوم \\
\hline 0.8314 & 3500 & 120 & 4.922 & 0.143 & 2.910 & 3 & 738 & عرابي 35 & \\
\hline 0.7630 & 4742.857 & $125-120$ & 0.649 & 0.0 & 3.619 & 321 & 233310 & 20.86 & \\
\hline 0.6649 & 5730 & 135 & 0.623 & 0.031 & 3.810 & 400 & 343783 & جيزة 178 & \\
\hline 0.6195 & 5980 & 140 & 0.634 & 0.0 & 3.705 & 330 & 281828 & سخا 101 & \\
\hline 0.6314 & 5730 & 135 & 0.854 & 0.031 & 3.618 & 199 & 159099 & سخا 104 & متوسط العمر \\
\hline 0.6992 & 5495 & 135 & 0.774 & 0.030 & 3.842 & 140 & 100280 & سخا 108 & $140-130$ \\
\hline 0.6634 & 5730 & 135 & 0.967 & 0.037 & 3.801 & 2 & 182 & هجين مصر 1 & \\
\hline 0.6550 & 5733 & $140-130$ & 0.361 & 0.014 & 3.755 & 1071 & 885172 & 79.14 & \\
\hline 0.7144 & 5237.929 & & 0.314183 & 0.011757 & 3.742 & 1392 & 1118482 & 100 & الاجمالى العام \\
\hline
\end{tabular}

المصدر: حسبث من بيانات تقدير محصول الأرز بطريقة العينات ومسوح المعاينة الخاصة بالبحث، ومركز البحوث الزراعية ، بحوث الأرز

جدول 3. ترتيب أصناف محصول الأرز حسب المساحة وكفاءة إنتاجية الفان وانتاجية المتر المكب من المياه

\begin{tabular}{|c|c|c|c|c|c|c|}
\hline \multicolumn{2}{|c|}{ انتاجية م من المياه } & \multicolumn{2}{|c|}{ انتاجية القدان } & \multirow{2}{*}{ المتيباحة } & \multirow[t]{2}{*}{ الصنف } & \multirow[t]{2}{*}{ البند } \\
\hline الكفاءة & ترتيب & الكفاعة \% & ترتيب & & & \\
\hline 107.8 & 5 & 98.7 & 6 & 3 & جيزة 177 & \\
\hline 121.0 & 3 & 97.1 & 8 & 6 & سخا 107 & \\
\hline 113.5 & 4 & 104.0 & 2 & 8 & جيزة 179 & \\
\hline 103.3 & 8 & 94.6 & 11 & 9 & سخا 105 & قصيرة العمر \\
\hline 103.3 & 7 & 96.4 & 9 & 10 & سخا 106 & 120- 125 يوم \\
\hline 152.5 & 1 & 106.4 & 1 & 7 & سوبر 300 & \\
\hline 126.9 & 2 & 77.5 & 12 & 11 & عرابي 35 & \\
\hline 116.5 & & 96.4 & & & الاجمالى & \\
\hline 101.5 & 9 & 101.5 & 4 & 1 & جيزة 178 & \\
\hline 94.6 & 12 & 98.7 & 7 & 2 & سخا 101 & \\
\hline 96.4 & 11 & 96.4 & 10 & 4 & سخا 104 & متوسط العمر \\
\hline 106.7 & 6 & 102.3 & 3 & 5 & سخا 108 & $140-130$ \\
\hline 101.3 & 10 & 101.2 & 5 & 12 & هجين مصر 1 & \\
\hline 100 & & 100 & & & الاجمالى & \\
\hline 109.1 & & 99.7 & & & 100 & عام \\
\hline
\end{tabular}

تم قياس الكفاءة بالنسبة للاصناف متوسطة العمر. انتاجية المتر المكعب منوسط العمر = 100 (0.655 كجم/23 من المياه)
(2) المصدر : حسبت من جدول رقئ (انتاجية الفدان متوسط العمر = 100 (3.755 طن/فدان) (2. 
- الصنف سوبر 300 حقق لدى الزراع منوسط 3.595 - 3.595 طن طن للفدان مقابل 4.5- 5.5 طن للفدان للبحوث.

2- الأصناف متوسطة العمر:

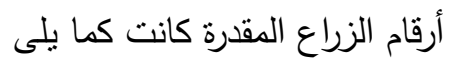
- - جيزة 178 نحو 3.81 طن/فدان. - سخا 101 نحو 3.705 طن/فدان. - سخا 104 نحو 3.618 طن/فدان. - سخا 108 نحو 3.842 طن/فدان.

المفروض حسب بيانات البحوث يتراوح الانتاجية بين

$$
4.2
$$

- وبالنسبة لصنف هجين مصرى1 فقد حقق الزراع نحو 3.801 طن/فدان فقط مقابل 5.5 - 6 طن/فدان. ومعنى ذللك وجود فجوة بين انتاجية زراع محصول الأرز وبين بيانات الهيئات البحثية تتراوح بين 1-2 طن للفدان.
ثالثا: المقارنة بين انتاجية أصناف محصول الأرز لاى زلاع المحصول وما يقابلها من أرقام الهيئات البحثية: يوضح جدول رقم (4) متوسطات أصناف الأرز كتوصيات الهيئات البحثية: - البيات 1- الأصناف قصيرة العمر 120-125 يوم: - الصنف جيزة 177 حقق لاى الزراع منوسط 3.708 طن للفدان مقابل 3.5-4.3 طن للفدان للبحوث.

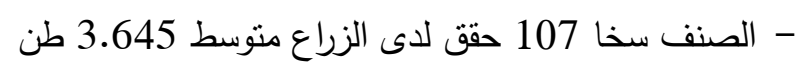
للفدان مقابل 4.2- 5 طن للفدان للبحوث. - الصنف جيزة 179 حقق لدى الزراع منوسط 3.904 طن للفدان مقابل 4.5- 5 طن للفدان للبحوث.

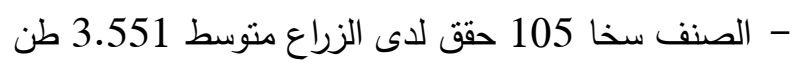
للفدان مقابل 4- 4.5 طن للفدان للبحوث. - الصنف سخا 106 حقق لاى الزراع منوسط 3.8 كن 3.619 طن للفدان مقابل 4.3- 4.8 طن للفدان للبحوث.

\begin{tabular}{|c|c|c|c|}
\hline & 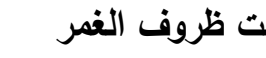 & 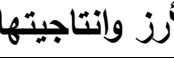 & ول يوضح أص \\
\hline \multirow{2}{*}{ الاحتياجات المائية القصوى } & فترة مكث المحصول & الانتاجية & \multirow{2}{*}{ الصنف } \\
\hline & (يوم) & طن/فان & \\
\hline \multicolumn{4}{|c|}{ 1- أصناف قصبرة العمر : 120-125 يوح } \\
\hline \multirow{7}{*}{ 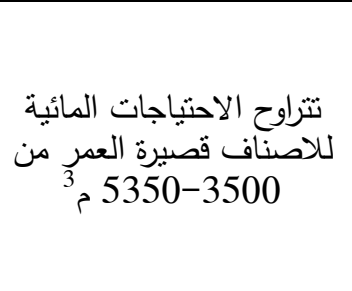 } & 125 & $4.3-3.5$ & جيزة 177 \\
\hline & 125 & $5-4.2$ & 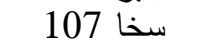 \\
\hline & 125 & $5-4.5$ & جيزة 179 \\
\hline & 125 & $4.5-4$ & 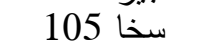 \\
\hline & 127 & $4.8-4.3$ & 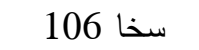 \\
\hline & 122 & $5.5-4.5$ & سوبر 300 \\
\hline & 120 & $5-4.2$ & 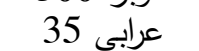 \\
\hline \multicolumn{4}{|c|}{ 2- أصناف منوسطة العمر : 130-140 يوم } \\
\hline \multirow{5}{*}{ للاصنافح الاحتياجة العمر المائيه } & 135 & $5-4.2$ & جيزة 178 \\
\hline & 140 & $5-4.2$ & 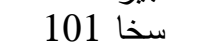 \\
\hline & 135 & $5-4.2$ & سخا 104 \\
\hline & 135 & $5-4.2$ & سخا 108 ( 10 \\
\hline & 135 & $6-5.5$ & هجين مصر 1 \\
\hline
\end{tabular}


منى عبد الحليم طلعت.: الجدارة الانتاجية والمائية لأهم أصناف محصول الأرز في جمهورية مصر العربية.

جدول 5. المساحة المحصولية والمقنن المائى للحقل للمحاصيل الصيفية عام 2019

\begin{tabular}{|c|c|c|c|c|c|c|c|c|c|c|c|c|}
\hline \multicolumn{2}{|c|}{ اجمالى الاستهلاك } & \multicolumn{2}{|c|}{ المتوسط العام للقدان } & \multirow[b]{2}{*}{$\%$} & \multicolumn{4}{|c|}{ المقنن المائى بالمتر المكب للفدان } & \multicolumn{3}{|c|}{ المحصولية } & \multirow[b]{2}{*}{ المحاصيل } \\
\hline$\%$ & الف م³ & $\%$ & $3^{3}$ & & مصر & $\%$ & الوسطى & $\%$ & وجرى & $\%$ & فان الف & \\
\hline 1.97 & 463512 & 44.19 & 2136 & 71.89 & 4570 & 92.59 & 4250 & 53.32 & 2369 & 4.46 & 217 & القطن \\
\hline 13.20 & 3105359 & 227.00 & 10973 & 174.71 & 11106 & 222.03 & 10191 & 180.17 & 8005 & 5.81 & 283 & قصب السكر \\
\hline 33.07 & 7781648 & 84.55 & 4087 & 76.03 & 4833 & 99.98 & 4589 & 77.45 & 3441 & 39.11 & 1904 & الذرة الثنامية \\
\hline 6.03 & 1418526 & 89.74 & 4338 & 70.47 & 4480 & 91.24 & 4188 & 78.12 & 3471 & 6.72 & 327 & الذرة الرفيعة \\
\hline 33.94 & 7987171 & 135.77 & 6563 & 121.19 & 7704 & 165.16 & 7581 & 147.60 & 6558 & 25.00 & 1217 & الأرز \\
\hline 0.04 & 8702 & 90.01 & 4351 & 75.68 & 4811 & 97.36 & 4469 & 86.00 & 3821 & 0.04 & 2 & البصل كامل النضج المنفرد \\
\hline 0.50 & 117771 & 65.85 & 3183 & 62.32 & 3962 & 80.54 & 3697 & 68.69 & 3052 & 0.76 & 37 & الفول السودانى \\
\hline 0.58 & 137083 & 97.79 & 4727 & 75.95 & 4828 & 104.01 & 4774 & 81.77 & 3633 & 0.60 & 29 & فول الصويا \\
\hline 0.67 & 158208 & 68.18 & 3296 & 61.41 & 3904 & 79.39 & 3644 & 68.58 & 3047 & 0.99 & 48 & السمسم \\
\hline 0.11 & 26352 & 68.14 & 3294 & 58.17 & 3698 & 75.29 & 3456 & 64.93 & 2885 & 0.16 & 8 & عباد الثمس \\
\hline 0.10 & 23960 & 61.96 & 2995 & 53.09 & 3375 & 68.19 & 3130 & 54.49 & 2421 & 0.16 & 8 & برسيم حجازى \\
\hline 3.10 & 729300 & 59.16 & 2860 & 59.49 & 3782 & 76.97 & 3533 & 54.51 & 2422 & 5.24 & 255 & العلف الاخضر \\
\hline 0.36 & 83847 & 91.29 & 4413 & 78.18 & 4970 & 96.12 & 4412 & 78.64 & 3494 & 0.39 & 19 & النباتات الطبية والعطرية \\
\hline 5.87 & 1382146 & 55.63 & 2689 & 64.86 & 4123 & 80.81 & 3709 & 53.95 & 2397 & 10.56 & 514 & الخضروات \\
\hline 100 & 23531912 & 100 & 4834 & 100 & 6357 & 100 & 4590 & 100 & 4443 & 100 & 4868 & الإجمالى \\
\hline
\end{tabular}

المصدر : جمعت وحسبث من بيانات الجهاز المركزى للتعبئة العامة والاحصاء (نشرة الموارد المائية عام 2019)

وهذا المقنن 6563 م|فدان يعتبر مغالى فيه نظرا لعدم اخذه فى الاعتبار الأصناف الحديثة من الأرز قصيرة العمر والموفرة لمياه الرى. بدليل أن هذا المقنن لم يتغير منذ أكثر من 20 عام حيث كان ييلغ نحو 6668 متر مكعب للفدان عام 2010. وبناء على هذا المقنن فإن اجمالى الاستهلاك المائى للأرز عام 2019 يبلغ نحو 7.9 مليار م كما يوضح الجدول رقم (5) أن المقنن المائى لمحصول الذرة الثامية بلغ نحو 4087 م|فدان فى المتوسط وأن أقصى مقنن مائى كان لمحصول قصب السكر حيث بلغ نحو 10973 م/فدان فى ملى ماسيط
رابعا: الاستهلاك المائى لمحصول الأرز عام 2019: وفقا لبيانات وزارة الموارد المائية والرى: يوضح جدول رقم (5) المساحة المحصولية والمقنن المائى للمحاصيل الصيفية عام 2019 وهو آخر بيان صدر عن وزارة الموارد المائية والرى. ويتضح منها أن متوسط المقنن المائى لمحصول الأرز بلغ نحو 6563 منر مكعب ورأب للفدان وأن إجمالى استهلاك الأرز من المياه عام 2019 بلغ لغ لغ نحو 7.98 مليار منز مكعب يمثل نحو 33.94\% من اجمالى الاستهلاك المائى للمحاصيل الصيفية. 
جدول 6. الاستهلاك المائى لمحصول الأرز عام 2020

\begin{tabular}{|c|c|c|c|c|c|c|}
\hline \multicolumn{2}{|c|}{ كمية المياه المتتهكة } & \multicolumn{2}{|c|}{ المقنن المائحي } & \multicolumn{2}{|c|}{ المساحة المحصولية } & \multirow{2}{*}{ الأصناف } \\
\hline$\%$ & مليار متر مكعب & $\%$ & متر مكب/فذان & $\%$ & فدان & \\
\hline 18.89 & 1.107 & 90.55 & 4743 & 20.86 & 233310 & قصبرة العمر \\
\hline 86.62 & 5.075 & 109.45 & 5733 & 79.14 & 885172 & متوسطة العمر \\
\hline 100 & 5.859 & 100 & 5238 & 100 & 1118482 & \\
\hline
\end{tabular}

الصصدر : حسبت من بيانات تقلير محصول الأرز بطرية العينات عام 2020، مركز البحوث الزراعية، قسم بحوث الأزز ، معهد بحوث المحاصيل الحقلية.

2-بنطبيق التوصيات والتعليمات الفنية الخاصة لكل صنف،

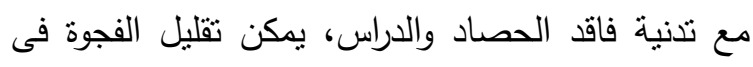

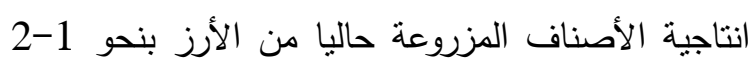
طن/فدان.

3- استمرار عملية نقيبم الجدارة الانتاجية والمائية باستخدام

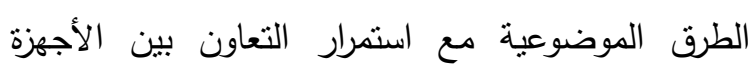
البحثية والتنفيذية.

4- الاستمرار في استتباط أصناف جديدة عالية الانتاجية

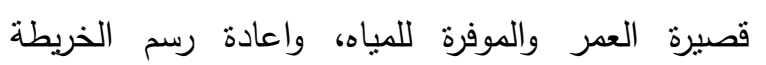

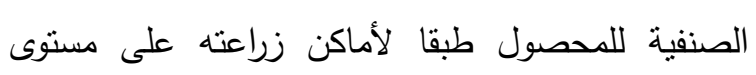
محافظات زراعة محصول الأرز.

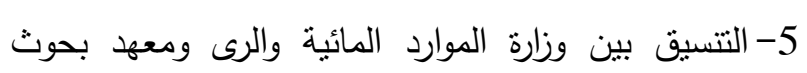

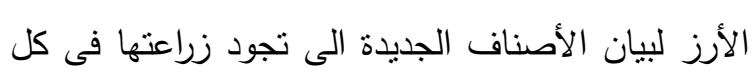

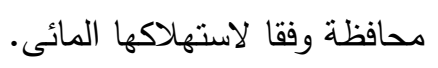

\section{المراجع}

تقدير محصول الأرز بطريقة العينات عام 2020، الإدارة العامة للعينات، قطاع الثئون الاقتصادية، وزارة الزراعة.

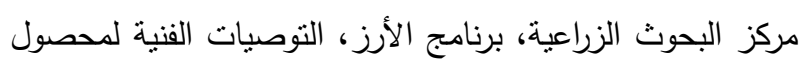

$$
\text { الأرز، اليحرث الزراعة. }
$$

محمود عبسى منصور ، رمزى محمد مبارك، "العلاقات التتافسية بين الأرز والذرة الثامية في استخدام مياه الري (دراسة حالة

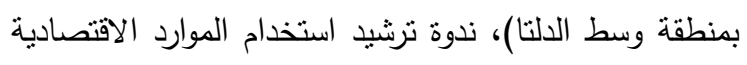

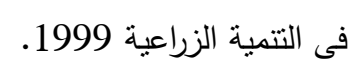

ويوضح الجدول رقم (6) الاستهلالك الفعلى لـحصول الأرز عام 2020 ويتضح من الجدول أن اجمالى المساحة

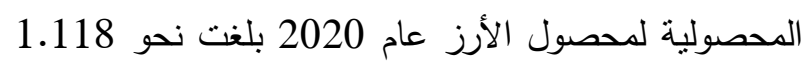

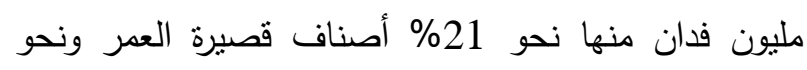
79 منوسطة العمر .

وأن منوسط المقنن المائى للأصناف قصيرة العمر بلغ

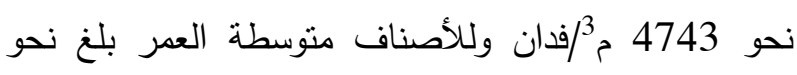
5733 مُ3/فدان. نحو كما يوضح الجدول رقم (6) أن إجمالى الكميات المستهلكة من المياه لأصناف الأرز بلغ نحو 5.859 مليار

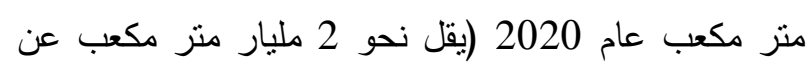

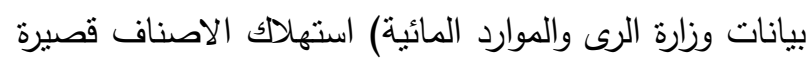

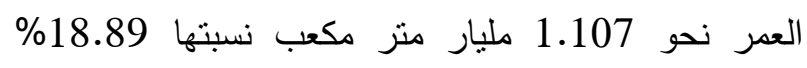
ومتوسطة العمر نحو 5.075 مليار متر مكعب نسبتها نحو مكو نسئه $\% 86.62$

ويتضح مما سبق أن احلال الأصناف قصيرة العمر محل

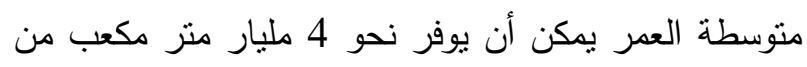
المياه.

\section{التوصيات}

1-يفضل زيادة مساحة الأصناف التى تتصف بالجدارة

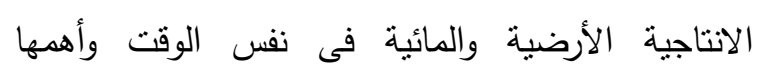
الأصناف سوبر 300 وجيزة 179 وسخا 108 وجيزة الأنية

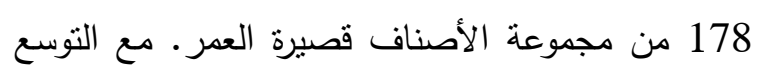

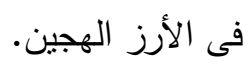




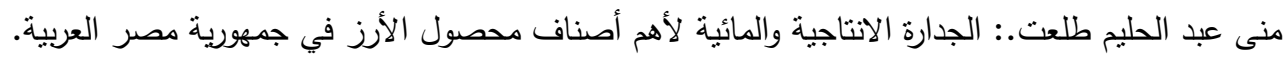

رمزى محمد مبارك، "تقدير الإنتاج الزراعي بطريقة العينات

الماضي والحاضر وتحديات المستقبل 1955-2005"، ندوة

معهد بحوث الاقتصاد الزراعي، ديسمبر 2005.

الجهاز المركزي للتعبئة العامة والإحصاء، النشرة السنوية لإحصاء

الري والموارد المائية.

Koshal,R,Si, Said, M, E: A Note on the pilot crop-cutting Expermental Surveys on Cotton and paddy conducted in 1955 in Daqahliya province, Egypt.

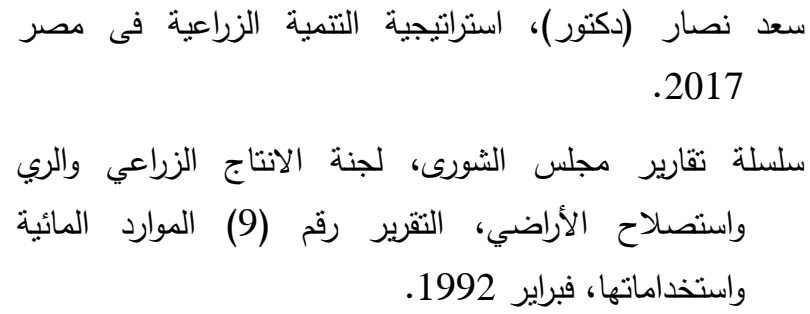

.2017

ABSTRACT

\title{
Productive and Water Merit of the Most Important Varieties of Rice in the Arab Republic of Egypt
}

\author{
Mona Abd El Halim Talaat Hussein
}

The Ministry of Agriculture strategy aims to optimizing the use of agricultural resources and increasing the agricultural productivity of the land and water units.

Given the limited share of natural water resources in Egypt which is about 55.5 billion cubic meters, in addition to the limited quantities of groundwater and the lack of rain, the agricultural development strategy aims to rationalize the uses of irrigation water in agriculture for various crops, especially the rice crop.

Since the rice crop is consumes alone about $30 \%$ of the total consumption of summer crops. Therefore, the rice research program, starting in 1990, aimed to develop short-lived and high-yield varieties to provide a large part of the irrigation water estimated at $20-30 \%$.

The research aims to assess the land and water productivity of rice crop varieties among farmers in the year 2020, so that it can help in developing a realistic strategy for the varieties that achieve the highest productivity with optimal use of irrigation water.

The research problem is that although old, lowproductivity and voracious varieties for consuming water have been replaced by new, high-yield and watersaving varieties of rice, the rice crop is still seen as consuming large amounts of irrigation water, which negatively affects other crops and thus affects the horizontal expansion of agricultural crops.

Many of the rice growers have not yet achieved the economic yield, and the Bulletin of statistics focus on calculating the productivity of the feddan without caring about the water productivity of the rice crop.
The research was based on objective methods based on the principle of sampling and actual measurement known as Crop Cuting.

\section{The most important results:}

First: The relative importance of the rice crop varieties in 2020:

The total area of the rice crop in 2020 was about 1.1 million feddans, about $84 \%$ of which were for the Giza 178 (30.7\%) variety, followed by the Sakha 101 $(25.2 \%)$, then the Giza 177 (14.3\%) variety, then the Sakha $104(14.2 \%)$ variety, and the rest of the variety occupied about $15 \%$ only.

The productivity of Rice this year was estimated at 3.74 tons/feddan, with a standard error of about 0.0117 ton/feddan $(0.31 \%$ of the average). Accordingly, the total production of the rice crop in 2020 amounted to about 4.19 million tons.

Second: The Productive and Water Efficiency of the most Important Varieties of the Rice Crop:

1- Short-lived varieties (120-125 days): irrigation water consumption is between $3500-5350$ cubic meters per feddan. The area of short-lived varieties reached about 0.233 million feddans, representing about $20.86 \%$ of the total rice area. the average production was estimated at 3.619 tons/feddan, with a standard error of about 0.023 ton/feddan. The average consumption of short-lived varieties of irrigation water was about 4742 cubic meters per feddan. The average production per cubic meter of water was about $0.7630 \mathrm{~kg} / \mathrm{m} 3$.

The most important high-productivity and watersaving varieties in this category, arranged in descending 
according to productivity as follows: Sakha super 300, Giza 179, Giza 177, Sakha 107, and Sakha 106.

2- Medium-lived varieties (130-140 days): irrigation water consumption ranged between 5495-5980 cubic meters per feddan. The area of medium-lived varieties reached about 0.885 million feddans, representing about $79.14 \%$ of the total area of the rice crop in 2020. The productivity of these varieties was estimated at about 3.755 ton/feddan of rice, with a sampling error of about 0.014 ton/feddan by about $0.361 \%$. The average consumption of the mediumlived varieties of irrigation water was about 5733 cubic meters per feddan. The average production per cubic meter of water was about $0.655 \mathrm{~kg} / \mathrm{m} 3$.

The most important high-productivity and watersaving varieties in this category, arranged in descending according to productivity as follows: Sakha 108, Giza 178, Hybrid 1, Sakha 101, then Sakha 104.

Third: The gap between the productivity of rice crop varieties for farmers and the data of the rice research program:
The gap between the productivity of rice crop growers compared to the data of the rice research program was between 1-2 ton/feddan on average, this deficit means the possibility of increasing productivity and production rice crop by following the recommendations of the rice research program and increasing the effectiveness of Agricultural Guidance.

Fourth: Water ration and consumption of the rice crop from irrigation water:

According to the data of the Ministry of Water Resources and Irrigation, the water ration of the rice crop amounted to about 6563 cubic meters per feddan and that the consumption of the rice crop amounted to about 7.9 billion cubic meters, representing about $33.9 \%$ of the total consumption of summer crops.

While the new short- and medium-lived varieties reduced the average water ration to about 5238 cubic meters per feddan, which resulted in a decrease in the quantities of water used from the rice crop in 2020 to about 5.859 billion cubic meters. The expansion of the cultivation of short-lived varieties could save an additional 4 billion cubic meters 